\title{
Complementary and Alternative Medicine (CAM) Utilization by Howard University (HU) First Year Pharmacy Students: Survey and Review of Most Commonly Used Herbs
}

Bisrat Hailemeskel PharmD ${ }^{1}$, Enaefe Ziregbe ${ }^{1}$, Christine Tran $^{1}$, Salome Bwayo Weaver PharmD, BCGP ${ }^{1}$, Aida Ahari-Lahagh ${ }^{1}$, Solomon Kumarra ${ }^{1}$, Fekadu Fullas $\mathrm{PhD}^{2^{*}}$, Anteneh Habte $\mathrm{MD}^{3}$

Hailemeskel B, Ziregbe E, Tran C, et al. Complementary and Alternative Medicine (CAM) Utilization by Howard University (HU) First Year Pharmacy Students: Survey and Review of Most Commonly Used Herbs. Curr Res Integr Med 2017;2(3): 37-41

\section{ABSTRACT}

An electronic questionnaire was utilized to conduct a survey on complementary and alternative medicine (CAM) use among first year Howard University pharmacy students. 36 out of 49 completed the questionnaire for a response rate of $73.5 \% .21(58.3 \%)$ reported having used herbs or other supplements in the past 5 years with cranberry, garlic, ginger and ginseng topping the list. Prayer (48\%) and Yoga (32\%) were the most commonly utilized non-herbal CAM modalities. Our finding is consistent with other studies, including one by the same authors, that CAM is a widely practiced modality in diverse segments of the US population.

Key Words: Survey and review; CAM; Herbs; Howard University first year pharmacy
$\mathrm{C}$ omplementary and alternative medicine (CAM) is a collection of diagnostic and therapeutic practices not generally utilized in conventional medicine (1). CAM may include modalities such as herbal supplements, spiritual or physical practices, and Chinese medicine (1). The 2012 National Health Interview Survey (NHIS) revealed that approximately thirty-three percent of adults use CAM with natural products being the most popular (2). Natural products, which include herbals and botanicals, are defined as dietary ingredients under the Dietary Supplement Health and Education Act of 1994 (DSHEA). In contrast to prescription drugs, dietary supplements such as herbs may be produced and marketed without first demonstrating safety or efficacy; it is only when the Food and Drug Administration (FDA) proves that a supplement is unsafe that a product can be removed from the market $(3,4)$. This paper evaluates in an alphabetical order the nine most commonly used herbs among first year pharmacy students at Howard University. These are black cohosh, cranberry, Echinacea, garlic, ginger, ginkgo, ginseng, milk thistle and saw palmetto.

Black cohosh (Actaea racemosa) is a native plant to North America. It is a member of the buttercup family with active ingredients that include actein and cimifugoside $(5,6)$. Black cohosh is most commonly used for menstrual/ menopause related symptoms including hot flashes, cramps, bloating and mood changes despite a paucity of clinical studies to support its use in this setting (7). A randomized double-blind control trial on women with anxiety disorder due to menopause concluded that there was no difference in the reduction of anxiety for women on black cohosh compared to placebo (7). However, the American College of Obstetricians and Gynecologists (ACOG) still recognizes the utility of black cohosh in relieving menopausal symptoms (8). Other common uses of this herb are in induction of labor, arthritis and osteoporosis $(5,6)$. Black cohosh is best avoided in children and pregnant and lactating women, although there is no clear evidence of adverse effects. There are no known major drug-herb interactions with black cohosh with the exception of a possible interaction with tamoxifen (6). The mechanism of action for black cohosh is not clear, but it is believed to have a modulatory effect on the estrogen receptor, and alternatively on serotonin receptors (8). Black cohosh is available in the form of capsules, tablets, tinctures, and extracts. No optimal effective dose has been established for black cohosh, but the commonly recommended initial adult dose is $20 \mathrm{mg}$ to $80 \mathrm{mg}(7,9)$. A clinical trial conducted by the National Center for Complementary and Integrative Health $(\mathrm{NCCIH})$ demonstrated that those who have taken black cohosh for as long as 12 months did not experience serious harmful effects (10).
Cranberry (Vaccinium macrocarpon) is a shrub native to North America and has been historically used by early settlers from England to treat bladder and kidney diseases (11). It is rich in antioxidants such as Vitamin C and flavonoids, and its mechanism of action is through the inhibition of the adherence of type 1 fimbriated Escherichia coli (11-13). Cranberry products have long been used to prevent urinary tract infections (UTIs) in premenopausal women and are widely available in the United States in a variety of formulations including juice, capsules, tablets, and powder $(14,15)$. Several studies which had demonstrated the effectiveness of cranberries in reducing the number of symptomatic UTIs in women with recurrent infections $(16,17)$ have been contradicted by a 2012 review of twenty-four clinical trials which concluded that cranberry juice and supplements do not prevent UTIs and that many of the existing studies were of poor quality (18). Cranberry may potentiate bleeding with blood thinners such as aspirin or warfarin, due to an ingredient similar to aspirin, salicylic acid (19).

Echinacea is one of the most widely used herbal products in the United States (20). There are nine known different species of Echinacea, and they contain different chemicals, such as glycoproteins, polysaccharides, alkamides, and volatile oils (20). For centuries, Echinacea has been used to treat scarlet fever, syphilis, malaria, and blood poisoning, but its popularity declined after the introduction of antibiotics (21). It is important to take the necessary precaution when using Echinacea products, because of the possible interactions with antifungal agents (e.g. econazole), immune-suppressants and caffeine (21). Studies suggest Echinacea contains ingredients which enhance the immune system, relieve pain, and provide anti-inflammatory, antiviral and antioxidant activity (22). Although treatment of common cold with Echinacea does not seem to be beneficial, there is some evidence that it may have a preventive effect (22). Commercially, Echinacea is available as tinctures, extracts, tablets, capsules and ointments. Its use for the treatment of upper respiratory tract conditions is not recommended in the pediatric population due to its lack of effectiveness and potential side effects $(21,23)$.

Garlic (Allium sativum) is native to Central Asia and the Middle East and has been used for medicinal purposes since the 18th century (24). It has beneficial chemical components such as allicin (25) which has the ability to cross phospholipid bilayers, human red blood cell membranes, and biological or artificial membranes by interaction with sulfhydryl groups (26). Garlic has been used for atherosclerosis, dyslipidemia, hypertension and a variety of cancers (27-30). The formulations of garlic include tablets, soft gels and oils

${ }^{1}$ Howard University College of Pharmacy, NW, Washington, USA ${ }^{2}$ UnityPoint Health-St. Luke's, Pharmacy Department, Iowa, USA ${ }^{3}$ Veterans Affairs Medical Center, Martinsburg, West Virginia University School of Medicine, Harpers Ferry, USA

Correspondence: Dr. Fekadu Fullas, UnityPoint Health-St. Luke's, Pharmacy Department, 2720 Stone Park, Boulevard, Sioux City, Iowa, 51104. USA, Telephone 712-2666156, e-mail Fekadu.Fullas@unitypoint.org or FeFuBal@aol.com

Received: October 28, 2017, Accepted: November 23, 2017, Published: December 04, 2017 
(31). Further studies are required to determine if garlic has any protective effects against stomach and colorectal cancer as separate meta-analyses by Fleischauer and $\mathrm{Hu}$ came to conflicting conclusions $(32,33)$. Garlic may interact with birth control medications, cyclosporine, anticoagulants, protease inhibitors, and nonsteroidal anti-inflammatory agents (NSAIDs) (34-36).

Ginger (Zingiber officinale) has been used for centuries in China for medicinal and culinary purposes. The chemical components of ginger include gingerols and shogaols (37). Shogaol is a selective 5-HT3 receptor antagonist which accounts for its anti-emetic properties. It is therefore often used to prevent nausea and vomiting associated with pregnancy, motion sickness, and chemotherapy (38-42). A meta-analysis of clinical trials conducted by Thomson et al. showed that ginger produced a 5 -fold likelihood of improvement in nausea and vomiting in early pregnancy (43). Ginger has also been commonly used for arthritis, pain, and heart disease $(44,45)$. It is available as a fresh or dried root, capsule, tea, bread, and dried stick (46). Ginger also has anticoagulant, antihyperglycemic and antihypertensive properties and caution has to be exercised during concomitant use with prescribed medications that have similar effects (47-49).

Ginkgo (Ginkgo biloba) is a Chinese tree species with short branches and fan-shaped leaves (50). Although there are more than 40 components in ginkgo, flavonoids and terpenoids are the only two components that have medicinal benefits (51). Ginkgo has been commonly used for anxiety, Alzheimer's disease, and intermittent claudication. It is available in several formulations, including capsules, tablets, and powders (52-56). A metaanalysis by Weinmann et al. showed ginkgo to be more effective than placebo in improving cognition in patients with Alzheimer's disease as well as vascular and mixed dementia (57). Ginkgo can interact with a wide range of medications metabolized by the liver including anticonvulsants, antidepressants, calcium channel blockers, anticoagulants, alprazolam, ibuprofen, cyclosporine, thiazide diuretics, and trazodone (58-60).

Ginseng belongs to the genus Panax, and the roots have been used for many centuries for a number of health benefits (61). The American ginseng (Panax quinquefolius) and the Asian ginseng (Panax ginseng) have similar chemical makeup, and both contain ginsenosides, which are believed to contain medicinal properties $(61,62)$. Ginseng is commonly used to reduce the risk of getting the cold or flu, and there have been various studies that suggest ginseng may help boost the immune system (63). In one study that compared ginseng to placebo for 12 weeks, the number of incidents of colds and symptoms of flu were two-thirds lower in the group that took ginseng (63). In addition to boosting the immune system, several studies suggest ginseng may also improve glucose metabolism, psychomotor function, and pulmonary disease; however, further studies of these benefits are needed (64). Ginseng is available as water and alcohol extracts, fresh root, dried root, tinctures, powders, capsules, and tablets (65). Despite the various studies that support its efficacy in treating different ailments, it has several possible interactions with blood thinning medications, and therefore concomitant use with the latter should be avoided (35). Adverse effects of ginseng include insomnia, tachycardia, decreased appetite, hypertension, euphoria, and neonatal death $(35,61,62)$.

Milk thistle (Silybum marianum) is native to Southern Europe, Southern Russia, and Asia, but also grows in North and South America (66). Historically, milk thistle has been used to treat liver problems, such as cirrhosis and hepatitis, in addition to kidney and gallbladder ailments (67). Silymarin, the main component of milk thistle, is known to protect the liver from acetaminophen and alcohol toxicity (66). Although limited by a small sample size and variations in dosing and duration, some studies seem to suggest that milk thistle improves liver function and overall survival in people with cirrhosis $(66,67)$. It is available as $120 \mathrm{mg}$ or $240 \mathrm{mg}$ capsules of silymarin, liquid extracts, or tinctures. Possible interactions of milk thistle with antipsychotics, phenytoin, and birth control pills have been documented (67) and side effects include stomach upset, diarrhea, rash, nausea and vomiting (68).

Saw palmetto (Serenoa repens) is a palm tree native to the United States (69). As a dietary supplement, it is commonly used to self-treat the symptoms of benign prostatic hyperplasia $(\mathrm{BPH})$, chronic pelvic pain, decreased sex drive, and hair loss $(69,70)$. Research has suggested it has anti-androgenic, anti-inflammatory, and anti-proliferative properties with similar effects to the alpha1 adrenergic blockers such as finasteride and dutasteride. Saw palmetto does not decrease prostate-specific antigen (PSA) levels (70). Due to its similar effects, concomitant use of saw palmetto with alpha-1 blocking agents is not recommended (71). More recently, there is a preponderance of evidence that Saw palmetto, even at higher doses, may not be better than placebo in its effectiveness in the treatment of BPH (70). Saw palmetto is available as dried berries, tea formulations, powder in capsules, tablets, liquid tinctures and liposterolic extracts.

Generally, saw palmetto is well tolerated with infrequent adverse events including abdominal pain, rhinitis, diarrhea, fatigue, and decreased libido (70-73).

\section{METHODS}

The survey tool used in this investigation was adapted from a study published on the use of CAM among Ethiopian immigrants in the USA. The survey was distributed to 49 first year pharmacy students as part of Drug Informatics Course, a mandatory course for first year professional pharmacy students. The goal of the course was to provide skills and knowledge of the various biomedical literature sources, including those that are related to alternative medicine. One of the topics in the course was to identify commonly used herbal products and know the various free internet and subscription-based drug information resources. One of us (BH) delivered the class lectures, and data were collected during these sessions. Participation in the survey was voluntary and students were given the option to complete it during the allotted time in class or later at their discretion and submit it to the instructor. Statistical analysis was done using SPSS.

\section{RESULTS}

A total of 36 first professional year pharmacy students participated in the study for a response rate of $73.5 \%$. Demographic data by age, gender, birth within or outside the US, level of education, annual income and medical insurance status of participants are shown in Table 1. As shown in Table 2, twenty-one respondents (58.3\%) had taken supplements/herbals in the past 5 years with the most commonly reported being cranberry, garlic, ginger, ginseng, saw palmetto, gingko, echinacea, black cohosh, and milk thistle. Other treatment modalities used by the survey respondents were prayer $48 \%(12 / 25)$, yoga $32 \%(8 / 25)$, chiropractor $4 \%(1 / 25)$, acupuncture/ massage/biofeedback $4 \%(1 / 25)$ and others $12 \%(3 / 25)$. The frequency of the supplement/herbal use was at least once a week for $62.1 \%(18 / 29)$ of the respondents, at least once a month for $10.3 \%(3 / 29)$, at least once a year for $17.2 \%(5 / 29)$, and at least once in 5 years for $10.3 \%(3 / 29)$. The ailments that were being treated included skin/wound problems, cough/ cold/sore throat, headache, arthritis pain, gastritis and stomach pain and other conditions. Nineteen respondents $(86.4 \%)$ reported benefiting from complementary modalities while three $(13.6 \%)$ reported no benefits. Only two respondents $(5.6 \%)$ experienced some side effects, such as nausea and vomiting while $26(72.2 \%)$ reported none at all. A majority of the herbs and supplements $72 \%(18 / 25)$ were purchased from CVS/retail stores, while $12 \%(3 / 25)$ were obtained from herbal/nutrition stores. $8 \%(2 / 25)$ were purchased online while $4 \%$ each $(1 / 25)$ came from friends and family or were imported from another country (Table 2).

\section{TABLE 1}

Demographic data of $\mathrm{HU}$ first professional year pharmacy students who use CAM

\begin{tabular}{cc}
\hline Characteristics & Valid Sample \% (proportion) \\
\hline Gender & \\
\hline Male & $41.7 \%(15 / 36)$ \\
Female & $58.3 \%(21 / 36)$ \\
\hline Age & \\
$<20$ & $5.6 \%(2 / 36)$ \\
$21-30$ & $83.3 \%(30 / 36)$ \\
$31-40$ & $11.1 \%(4 / 36)$ \\
\hline
\end{tabular}

\section{Born in the USA}

Yes

$63.9 \%(23 / 36)$

No $36.1 \%(13 / 36)$

\section{Level of prior education}

Some college

Associate degree/diploma

$14.3 \%(5 / 36)$

Associate degree/dip
BA/BSC

$8.6 \%(3 / 36)$

MSc or higher

$62.9 \%(22 / 36)$

$14.3 \%(5 / 36)$

\section{Annual income}

\begin{tabular}{cc}
\multicolumn{1}{c}{ Annual income } \\
\hline$\$ 50,000$ & $97.1 \%(33 / 36)$ \\
$\$ 100,000-\$ 150,000$ & $2.9 \%(1 / 36)$ \\
\hline Medical insurance & $100 \%(36 / 36)$ \\
Yes & $0 \%(0 / 36)$
\end{tabular}


TABLE 2

CAM use pattern by HU first year pharmacy students

\begin{tabular}{|c|c|}
\hline Responses & $\begin{array}{l}\text { Valid Sample \% } \\
\text { (Proportion) }\end{array}$ \\
\hline \multicolumn{2}{|c|}{ Taken supplements in the past 5 years } \\
\hline Yes & $58.3 \%(21 / 36)$ \\
\hline No & $38.9 \%(14 / 36)$ \\
\hline No Response & $2.8 \%(1 / 36)$ \\
\hline \multicolumn{2}{|c|}{ Frequency of CAM Use } \\
\hline At least once a week & $62.1(18 / 29)$ \\
\hline At least once a month & $10.3(3 / 29)$ \\
\hline At least once a year & $17.2(5 / 29)$ \\
\hline At least once in 5 years & $10.3(3 / 29)$ \\
\hline \multicolumn{2}{|c|}{ Name of herbal/supplement used } \\
\hline Cranberry & $16 \%(4 / 27)$ \\
\hline Garlic & $12 \%(3 / 27)$ \\
\hline Ginger & $12 \%(3 / 27)$ \\
\hline Ginseng & $12 \%(3 / 27)$ \\
\hline Saw palmetto & $8 \%(2 / 27)$ \\
\hline Gingko & $4 \%(1 / 27)$ \\
\hline Echinacea & $4 \%(1 / 27)$ \\
\hline Milk thistle & $4 \%(1 / 27)$ \\
\hline Black Cohosh & $4 \%(1 / 27)$ \\
\hline Other & $24 \%(8 / 27)$ \\
\hline \multicolumn{2}{|c|}{ Other alternative therapies } \\
\hline Prayer & $48 \%(12 / 25)$ \\
\hline Yoga & $32 \%(8 / 25)$ \\
\hline Chiropractor & $4 \%(1 / 25)$ \\
\hline Acupuncture/massage/biofeedback & $4 \%(1 / 25)$ \\
\hline Other & $12 \%(3 / 25)$ \\
\hline \multicolumn{2}{|c|}{ Ailments leading to herbal/supplement use } \\
\hline Respiratory (cough/cold) & $20 \%(1 / 5)$ \\
\hline Stomach (e.g. gastritis, pain) & $20 \%(1 / 5)$ \\
\hline Skin/wound problems & $20 \%(1 / 5)$ \\
\hline Pain/arthritis & $40 \%(2 / 5)$ \\
\hline \multicolumn{2}{|c|}{ Did complementary methods help? } \\
\hline Yes & $86.4 \%(19 / 22)$ \\
\hline No & $13.6 \%(3 / 22)$ \\
\hline \multicolumn{2}{|c|}{ Experienced side effects? } \\
\hline Only sometimes & $5.6 \%(2 / 28)$ \\
\hline Never & $72.2 \%(26 / 28)$ \\
\hline \multicolumn{2}{|c|}{ Source where herbals/supplements were obtained } \\
\hline CVS/other retail stores & $72 \%(18 / 25)$ \\
\hline Herbal/nutrition stores & $12 \%(3 / 25)$ \\
\hline Online suppliers & $8 \%(2 / 25)$ \\
\hline Friends/family & $4 \%(1 / 25)$ \\
\hline Obtained from another country & $4 \%(1 / 25)$ \\
\hline \multicolumn{2}{|c|}{ How did you learn about the herbals/supplements? } \\
\hline Friends/family & $48 \%(12 / 25)$ \\
\hline Internet & $40 \%(10 / 25)$ \\
\hline TV commercials & $8 \%(2 / 25)$ \\
\hline Other & $4 \%(1 / 25)$ \\
\hline
\end{tabular}

Three of these studies demonstrated a reduction in the progression of noncalcified plaque volume associated with statin therapy $(35,40,41)$. In addition, Inoue et al. showed that statin therapy results in a reduction of both plaque volume and necrotic core volume, implying improved plaque stability (42).

Recent randomized controlled trials have included assessments of coronary plaque from CCTA measurements, including plaque volume, composition and vulnerability $(39,43)$. Auscher et al. showed that early aggressive lipid lowering therapy increases dense calcium volume, but did not significantly affect plaque volume in patients with acute myocardial infarction (43). Lo et al. demonstrated a reduction in non-calcified plaque volume and other high-risk plaque features in a small group of HIV-infected patients treated with statins (39).

\section{DISCUSSION}

Our survey established that a majority $(58.3 \%)$ of first professional year pharmacy students used herbs and supplements over the last five years with
$62 \%$ of them reporting a frequency of at least once a week. Retail stores such as CVS were the most common sources, and it is highly likely that ease of access (proximity, availability, price, hours of operation, etc.) contributed to this pattern. Although Howard University provides health insurance to all students and office visits are free with no co-pay, limited office hours and long wait times coupled with the rigorous schedule of pharmacy school may make the conventional clinics less desirable for non-serious ailments. The results of this survey also showed that self-treatment options and alternative therapies such as prayer and yoga are frequently used at a rate of $48 \%$ and $32 \%$, respectively.

Regardless of the rational for using CAM, more than 85 percent of utilizers reported health benefits with only 2 experiencing side effects. As an overwhelming majority have been using CAM within the past 5 years, this practice is unlikely to be influenced by their training or education in pharmacy school. Moreover, the survey was conducted early in the year while the introductory class in herbal products is not offered until the end of the first didactic year at Howard University.

Cranberry was the most frequently used herb/supplement out of the nine listed in the survey. As it is most commonly used for urinary tract infection and approximately $50 \%-60 \%$ of women will develop UTIs in their lifetime (13), the female predominance of our respondents may have skewed the results. Garlic, ginger and ginseng were used in equal frequency. Other common ailments for which herbs/supplements were used include respiratory complaints, gastrointestinal tract symptoms, skin conditions and pain/arthritis (Table 2).

\section{LIMITATIONS}

Our sample size was small in part due to the unusually few cohorts accepted to the Howard University Pharmacy Program last year. The survey was administered to first year students only, because the Drug Informatics Course was offered to this group. The exclusion of students from other didactic years also precluded the opportunity to interpret whether the knowledge and training obtained from pharmacy school influenced CAM use. Additionally, the herbs listed in this survey were preselected by the investigators, and the data collected may not reflect a true representation of the types of herbs used. Furthermore, since there is such great diversity within the college of pharmacy, data on the ethnicity of participants should have been collected, as cultural traditions may influence the perception of CAM use. There is an opportunity for a follow-up study to determine whether ethnic background influences CAM use by pharmacy students.

\section{CONCLUSION}

About $53 \%$ of HU first year pharmacy students had used CAM in the past five years. Cranberry was the most frequently use product at the rate of $16 \%$, followed by garlic, ginger and ginseng, each at $12 \%$. Other most frequently used CAM modalities included prayers (33\%) and yoga (22.2\%). The majority of the respondents (86.4\%) reported health benefits from CAM and $72.2 \%$ did not experience adverse effects.

\section{REFERENCES}

1. National Center for Complementary and Integrative Health. The Use of Complementary and Alternative Medicine in the United States. NCCIH. 2016. Available at: https://nccih.nih.gov/research/ statistics/2007/camsurvey_fs1.htm

2. National Center for Complementary and Integrative Health. The Use of Complementary Approaches in the U.S. NCCIH. 2016. Available at: https://nccih.nih.gov/research/statistics/NHIS/2012/key-findings.

3. Bent S. Herbal Medicine in the United States: Review of Efficacy, Safety, and Regulation. J Gen Intern Med. 2008; 23(6): 854-859.

4. Tachjian A, Maria V, Jahangir A. Use of Herbal Products and Potential Interactions in Patients with Cardiovascular Diseases. J Am Coll Cardiol 2010; 55:515-525.

5. National Center for Complementary and Integrative Health. Black Cohosh. NCCIH. 2016. Available at: https://nccih.nih.gov/health/ blackcohosh/ataglance.htm

6. Benjamin K. Black Cohosh. Am Fam Physician 2003; 68(1):114-6.

7. Amsterdam JD, Yao Y, Mao JJ, et al. Randomized, double-blind, placebocontrolled trial of Cimicifuga racemosa (black cohosh) in women with anxiety disorder due to menopause. J Clin Psychopharmacol 2009; 29:478-483. 
8. Shahnazi M, Nahaee J, Mohammad-Alizadeh-Charandabi S, et al. Effect of Black Cohosh (Cimicifuga Racemosa) on Vasomotor Symptoms in Postmenopausal Women: A Randomized Clinical Trial” Journal Caring Science. J Caring Sci 2013; 2:105-113.

9. National Institutes of Health Dietary Supplement Label Database. https://www.dsld.nlm.nih.gov/dsld/rptQSearch.jsp?item=black+cohos h\&db=adsld.

10. Painter D, Perwaiz S, Murty M. Black cohosh products and liver toxicity: update. Canadian Adverse Reaction Newsletter 2010; 20:1-2.

11. National Center for Complementary and Integrative Health. Cranberry. NCCIH. 2016. Available at: https://nccih.nih.gov/health/cranberry

12. Dietz BM, Hajirahimkhan A, Dunlap TL, et al. Botanicals and Their Bioactive Phytochemicals for Women's Health. Pharmacol Rev 2016; 68:1026-1073.

13. Rossi R, Porta S, Canovi B. Overview of cranberry and urinary tract infections in females. J Clin Gastroenterol 2010; 44: S61-S62.

14. Cayley W. American Family Physician. Cochrane for clinicians: Are cranberry products effective for the prevention of urinary tract infections? [Accessed March 31, 2017]. Available at: http://www.aafp. org/afp/2013/1201/p745.html

15. Wang $\mathrm{CH}$, Fang $\mathrm{CC}$, Chen $\mathrm{NC}$, et al. Cranberry-containing products for prevention of urinary tract infections in susceptible populations: a systematic review and meta-analysis of randomized controlled trials. Arch Intern Med 2012; 172:988-996.

16. Stothers L. A randomized trial to evaluate effectiveness and cost effectiveness of naturopathic cranberry products as prophylaxis against urinary tract infection in women. Can J Urol 2002; 9:1558-1562.

17. Kontiokiari T, Sundqvist K, Nuutinen M, et al. Randomized trial of cranberry-lingonberry juice and Lactobacillus GG drink for the prevention of urinary tract infections in women. BMJ 2001; 322:1571.

18. Jepson RG, Williams G, Craig JC. Cranberries for preventing urinary tract infections. Cochrane Database Syst Rev 2012; 10:CD001321.

19. Aston JL, Lodolce AE, Shapiro NL. Interaction between warfarin and cranberry juice. Pharmacotherapy. 2006; 26:1314-1319.

20. Barrett B, Brown R, Rakel D, et al. Echinacea for treating the common cold: randomized trial. Ann Intern Med 2010; 153: 769-777.

21. Gurley BJ, Fifer EK, Gardner Z. Pharmacokinetic herb-drug interactions (part 2): drug interactions involving popular botanical dietary supplements and their clinical relevance. Planta Medica 2012; 78:1490-1514.

22. Di Pierro F, Rapacioli G, Ferrara T, et al. Use of a standardized extract from Echinacea angustifolia (Polinacea) for the prevention of respiratory tract infections. Altern Med Rev 2012; 17:36-41.

23. Taylor J, Weber W, Standish L, et al. Efficacy and safety of Echinacea in treating upper respiratory tract infection in children. JAMA 2003; 209:2824-2830.

24. Petrovska B, Cekovska S. Extracts from the history and medical properties of garlic. Pharmacogn Rev 2012; 4:106-110.

25. Cantwell M. Alliin in garlic. Perishables Handling Quarterly 2000; 102:5-6.

26. Talia M, Aharon R, David M, et al. The mode of action of allicin: its ready permeability through phospholipid membranes may contribute to its biological activity. Biochimica et Biophysica Acta (BBA) Biomembranes 2000; 1463:20-30.

27. Ashraf R, Aamir K, Shaikh AR, et al. Effects of garlic on dyslipidemia in patients with type 2 diabetes mellitus. J Ayub Med Coll Abbottabad 2005;17(3):60-64.

28. Berthold HK, Sudhop T. Garlic preparation for prevention of atherosclerosis. Curr Opin Lipidol 1998; 9:565-569

29. Caron MF, White CM. Evaluation of the antihyperlipidemic properties of dietary supplements. Pharmacotherapy 2001; 21:481-487.

30. Fleischauer AT, Poole C, Arab L. Garlic consumption and cancer prevention: meta-analyses of colorectal and stomach cancers. Am J Clin Nutr 2000; 72:1047-1052.
31. Banerjee S, Maulik S. Effect of garlic on cardiovascular disorders: A review. Nutrition Journal 2002; 1:1-14.

32. Gruhlke MC, Nicco C, Batteux F, et al. The effects of allicin, a reactive sulfur species from garlic, on a selection of mammalian cell lines. Antioxidants(Basel) 2016; 6:1.

33. Hu J, Hu Y, Zhou J, et al. Consumption of garlic and risk of colorectal cancer: an updated meta-analysis of prospective studies. World J Gastroenterol 2014; 20: 15413-15422.

34. Heck AM, DeWitt BA, Lukes AL. Potential interactions between alternative therapies and warfarin. Am J Health Syst Pharm 2000, $57: 1221-1227$.

35. Izzo AA, Ernst E. Interactions between herbal medicines and prescribed drugs: a systematic review. Drugs 2001; 69(13):1777-98.

36. Markowitz JS, Devane CL, Chavin KD, et al. Effects of garlic (Allium sativum L.) supplementation on cytochrome P450 2D6 and 3A4 activity in healthy volunteers. Clin Pharmacol Ther 2003; 74:170-177.

37. Ali BH, Blunden G, Tanira MO, et al. Some phytochemical, pharmacological and toxicological properties of ginger (Zingiber officinale Roscoe): a review of recent research. Food Chem Toxicol 2008; 46:409-420.

38. Abdel-Aziz H, Windeck T, Ploch M, et al. Mode of action of gingerols and shogaols on 5-HT 3 receptors: binding studies, cation uptake by the receptor channel and contraction of isolated guinea-pig ileum. Eur J Pharmacol 2006; 530:136-143.

39. Apariman S, Ratchanon S, Wiriyasirivej B. Effectiveness of ginger for prevention of nausea and vomiting after gynecological laparoscopy. J Med Assoc Thai 2006; 89:2003-2009.

40. Chaiyakunapruk N, Kitikannakorn N, Nathisuwan S, et al. The efficacy of ginger for the prevention of postoperative nausea and vomiting: a meta-analysis. Am J Obstet Gynecol. 2006; 194:95-99.

41. Pongrojpaw D, Somprasit C, Chanthasenanont A. A randomized comparison of ginger and dimenhydrinate in the treatment of nausea and vomiting in pregnancy. J Med Assoc Thai. 2007; 90:1703-1709.

42. Lee SH, Cekanova M, Baek SJ. Multiple mechanisms are involved in 6-gingerol-induced cell growth arrest and apoptosis in human colorectal cancer cells. Mol Carcinog 2008; 47:197-208.

43. Bliddal H, Rosetzsky A, Schlichting P, et al. A randomized, placebocontrolled, cross-over study of ginger extracts and ibuprofen in osteoarthritis. Osteoarthritis Cartilage 2000; 8:9-12.

44. Nicoll R, Henein MY. Ginger (Zingiber officinale Roscoe): A hot remedy for cardiovascular disease? Int J Cardilo 131.3 2009: 408-409.

45. White B. Ginger: An overview. Am Fam Physician 2007; 75:1689-1691

46. Thomson M, Corbin R, Leung L. Effects of ginger for nausea and vomiting in early pregnancy: A meta-analysis. JABFM 2014; 27:115-122.

47. Vaes L, Chyka P. Interactions of warfarin with garlic, ginger, ginkgo, or ginseng: nature of the evidence. Ann Pharmacother 2000; 34(12):1478-1482.

48. Khandouzi N, Shidfar F, Rajab A, et al. The effects of ginger on fasting blood sugar, hemoglobin A1c, apolipoprotein B, apolipoprotein A-I and malondialdehyde in type 2 diabetic patients. Iran J Pharm Res 2015; $14: 131-140$.

49. Ghayur MN, Gilani AH. Ginger lowers blood pressure through blockade of voltage-dependent calcium channels. J Cardiovasc Pharmacol $2005 ; 45: 74-80$

50. May B, Lit M, Xue C, et al. Herbal medicine for dementia: A systematic review. Phyother Res 2009;23:447-459.

51. Ude C, Schubert-Zsilavecz, M, Wurglics M. Ginkgo biloba extracts: A review of the pharmacokinetics of the active ingredients. Clin Pharmacokinet 2013;52:727-749.

52. DeKosky ST, Williamson JD, Fitzpatrick AL, et al. Ginkgo biloba for prevention of dementia: A randomized controlled trial. JAMA 2008; $300: 2253-62$

53. Ihl R. Effects of Ginkgo biloba extract EGb $761^{\circledR}$ in dementia with neuropsychiatric features: review of recently completed randomized, controlled trials. Int J Psychiatry Clin Pract 2013; 17:8-14. 
54. Ihl R, Tribanek M, Bachinskaya N. Efficacy and tolerability of a once daily formulation of Ginkgo biloba extract EGb761 in Alzheimer's disease and vascular dementia: results from a randomized controlled trial. Pharmacopsychiatry 2012; 45:41-46.

55. Woelk H, Arnoldt KH, Kieser M, et al. Ginkgo biloba special extract EGb 761 in generalized anxiety disorder and adjustment disorder with anxious mood: A randomized, double-blind, placebo-controlled trial. J Psychiatr Res 2007; 41:472-480.

56. Zheng B, Xing G, Bi Y, et al. Comparative pharmacokinetics of a proliposome formulation of Ginkgo biloba extract and Ginaton in rats by a sensitive ultra-performance liquid chromatography- tandem mass spectrometry method. Saudi J Biol Sci 2016; 23: 54-65.

57. Weinmann S, Roll S, Schwarzbach C, et al. Effects of Ginkgo biloba in dementia: A systematic review and meta-analysis. BMC Geriatr 2010;10:14

58. Kupiec T, Raj V. Fatal seizures due to potential herb-drug interactions with Ginkgo biloba. J Anal Toxicol 2005; 29: 755-758.

59. Ashton AK, Ahrens K, Gupta S, et al. Antidepressant-induced sexual dysfunction and Ginkgo Biloba. Am J Psychiatry 2000; 157:836-837.

60. Tachjian A, Maria V, Jahangir A. Use of herbal products and potential interactions in patients with cardiovascular diseases. J Am Coll Cardiol 2010; 55:515-525.

61. National Center for Complementary and Integrative Health. Ginseng. NCCIH. 2016. Available at: https://nccih.nih. health/asianginseng gov/

62. Coleman CI, Hebert JH, Reddy P. The effects of Panax ginseng on quality of life. J Clin Pharm Ther 2003;28:5-15

63. McElhaney JE, Goel V, Toane B,e $t$ al. Efficacy of COLD-fX in the prevention of respiratory symptoms in community-dwelling adults: A randomized, double-blind, placebo controlled trial. J Altern Complement Med 2006;12:153-157
64. Lee NH, Son CG. Systematic review of randomized controlled trials evaluating the efficacy and safety of ginseng. A review. J Acupunct Meridian Stud 2011;4:85-97.

65. American ginseng. www.umm.edu/health/medical/altmed/herbamericanginseng.

66. Fried MW, Navarro VJ, Afdhal N, et al. Effect of silymarin (Milk Thistle) on liver disease in patients with chronic hepatitis C unsuccessfully treated with interferon therapy: A randomized control trial. JAMA 2012; 308: $274-282$.

67. Siegal A, Stebbing J. Milk thistle: Early seeds of potential. Lancet Oncol 2013; 14:929-930.

68. C Mulrow, V Lawrence, B Jacobs, et al. Milk Thistle: Effects on liver disease and cirrhosis and clinical adverse effects: A summary. Agency for Healthcare Research and Quality 2000.

69. National Center for Complementary and Integrative Health. [Accessed March 31, 2017]. Saw Palmetto. NCCIH. 2016. Available at: https:// nccih.nih.gov/health/palmetto/ataglance.htm

70. Bent S, Kane C, Shinohara K, et al. Saw palmetto for benign prostatic hyperplasia. N Engl J Med 2006; 354:557-566.

71. Agbabiaka TB, Pittler MH, Wider B, et al. Serenoa repens (saw palmetto): A systematic review of adverse events. Drug Saf 2009; 32:637-647.

72. Avins AL, Lee JY, Meyers CM, et al. Safety and Toxicity of Saw palmetto in the Complementary and Alternative Medicine for Urological Symptoms (CAMUS) Trial. J Urol 2013; 189:1415-1420.

73. Gerber GS, Zagaja GP, Bales GT, et al. Saw Palmetto (Serenoa repens) in men with lower urinary tract symptoms: effects on urodynamic parameters and voiding symptoms. Urology 1998; 51(6):1003-1007. 